\title{
Climate Change and the Stability of Water Allocation Agreements
}

\author{
Erik Ansink • Arjan Ruijs
}

Accepted: 4 January 2008 / Published online: 1 February 2008

(C) The Author(s) 2008

\begin{abstract}
We analyse agreements on river water allocation between riparian countries. Besides being efficient, water allocation agreements need to be stable in order to be effective in increasing the efficiency of water use. In this paper we assess the stability of water allocation agreements using a game theoretic model. We consider the effects of climate change and the choice of a sharing rule on stability. Our results show that a decrease in mean river flow decreases the stability of an agreement, while an increased variance can have a positive or a negative effect on stability. An agreement where the downstream country is allocated a fixed amount of water has the lowest stability compared to other sharing rules. These results hold for both constant and flexible non-water transfers.
\end{abstract}

Keywords Climate change $\cdot$ Game theory $\cdot$ Stability $\cdot$ Water allocation

\section{Introduction}

When multiple countries share a river, they compete over available water resources. The upstream country has the first option to use water, which may obstruct the overall efficiency of water use (Barrett 1994). Cooperation between upstream and downstream countries-in the form of a water allocation agreement-may increase the efficiency of water use. Whether cooperation is stable, however, depends on the design of the water allocation agreement. The stability of water allocation agreements is the subject of this paper.

In the twentieth century, 145 international agreements on water use in transboundary rivers were signed; almost 50\% of these agreements cover water allocation issues (Wolf 1998). The majority of these water allocation agreements does not take into account the hydrologic variability of river flow (Giordano and Wolf 2003). This is a shortcoming because variability is an important characteristic of river flow. This variability will even increase in many river basins

E. Ansink (凶) - A. Ruijs

Environmental Economics and Natural Resources Group, Wageningen University,

P.O. Box 8130, Wageningen $6700 \mathrm{EW}$, The Netherlands

e-mail: erik.ansink@wur.nl 
when the effects of climate change on temperature and precipitation proceed as projected by climate simulation models (IPCC 2007b). These effects are expected to increase the variability of the annual and seasonal flow patterns as well as the frequency of extreme events in many river basins (Arnell 1999; Chalecki and Gleick 1999; Voss et al. 2002; Räisänen et al. 2004). Recognition of flow variability in the design of water allocation agreements can increase the efficiency of these agreements.

Several studies have addressed this issue for two common sharing rules for water allocation: proportional allocation and fixed flow allocation (for an overview of sharing rules, see Dinar et al. 1997). Fixed flow allocations are most common (Wolf 1998) but tend to be less efficient when flow variability increases. Bennett et al. (2000) compared the efficiency of fixed flow allocations with proportional allocations and found that, in many situations, proportional allocations are more efficient. Kilgour and Dinar (1995, 2001) developed a sharing rule that ensures a Pareto-efficient allocation for every possible flow volume, where the level of compensation paid by receivers of water is subject to annual bargaining. Obviously, compared with a proportional or fixed flow allocation, this flexible allocation is more efficient, but it requires accurate predictions of annual river flow and flexibility in compensation payments. In a case study of the Colorado river, Mendelsohn and Bennett (1997) found that the loss of efficiency related to a change in mean river flow (e.g. because of climate change) is higher for a proportional allocation than for a fixed allocation, the main reason being that the initial proportions used were inefficient. Another result was that the largest impact of climate change on efficiency comes from changes in the mean river flow, not from changes in the variance. Furthermore, in an analysis of US inter-state water allocation agreements, Bennett and Howe (1998) found that agreement compliance is higher for proportional than for fixed flow allocations.

Apart from being efficient, water allocation agreements need to be stable in order to be effective instruments to increase the efficiency of water use. Efficiency and stability of agreements are not necessarily linked. Climate change, for instance, may increase the benefits of cooperation to one country while decreasing those to the other, leaving overall efficiency equal, but possibly giving the country with decreased benefits an incentive to leave the agreement. Because agreements are signed between sovereign nations, there is usually no higher level authority that can enforce compliance. The stability of agreements therefore depends on the distribution of the benefits of cooperation to the countries involved, which can be analysed using game theory. Recent studies (Ambec and Sprumont 2002; Wang et al. 2003; Heintzelman 2004; Kucukmehmetoglu and Guldmann 2004; Wu and Whittington 2006) showed that water allocation agreements can improve the efficiency of water use and thatwhen benefits of cooperation are distributed properly-they can be attractive to all countries involved. This game theoretic literature, however, does not explicitly consider the effects of climate change on river flow and agreement stability.

The objective of this paper is to assess the stability of water allocation agreements when climate change affects river flow. This is done by constructing a game theoretic model of water allocation that analyses stability of three sharing rules for water allocation. Our results show that a decrease in mean river flow decreases the stability of an agreement, while an increased variance can have a positive or a negative effect on stability. An agreement where the downstream country is allocated a fixed amount of water has the lowest stability compared to other sharing rules. These results hold for both constant and flexible non-water transfers.

The remainder of this paper is organised as follows. In Sect. 2 we present background information for our model assumptions. In Sects. 3 and 4 we present our model and assess stability of cooperation. In Sect. 5 we assess stability effects of asymmetric countries. In Sect. 6 we illustrate the effects of climate change on the stability of cooperation for different 
sharing rules, using a numerical example. In Sect. 7 we discuss the results, and we conclude in Sect. 8.

\section{Setting the Stage}

There is no standard water allocation agreement that can serve as a basis for our model assumptions. Because of historical, hydro-geographical, economic, and political reasons, the institutional setting of agreements shows a large variety. In this section we provide some evidence for this variety. We focus on three institutional aspects of water allocation agreements that are important for our model assumptions: sharing rules, non-water transfers, and reactions to noncompliance.

\subsection{Sharing Rules}

The vast majority of international agreements on water allocation are bilateral. In fact, less than ten multilateral agreements on water allocation are listed in the International Freshwater Treaties Database (e.g. the 1955 Jordan agreement based on the Johnston negotiations, that was signed by Israel, Jordan, Lebanon, and Syria) (Beach et al. 2000). Because of this limited number of countries in a typical agreement, sharing rules are not complex. Generally, they are based on a combination of historical rights, economic efficiency and the principle of "reasonable and equitable sharing", as defined in the 1966 Helsinki Rules.

Two basic types of sharing rules are dominant. The first type, which is most common, applies a percentage rule. An example is the 1975 Euphrates Agreement (Iran, Iraq) in which the flows of the Bnava Suta, Qurahtu, and Gangir rivers were divided equally (Beach et al. 2000). The second type guarantees a fixed amount of water to one or both of the countries. An example is the 1959 Agreement between Nepal and India on the Gandak irrigation and power project, in which irrigation water was allocated for 40,000 acres in Nepal and 103,500 acres in India (Beach et al. 2000). Combinations of these sharing rules are common too. An example is the Nile Waters Agreement (Egypt, Sudan) that allocates 48,000 MCM/yr to Egypt and 4,000 MCM/year to Sudan, based on acquired rights. Of the remaining flow, 34\% is allocated to Egypt and 66\% to Sudan (NWA 1959).

\subsection{Non-water Transfers}

In basins where water is scarce, water use by upstream countries goes at the expense of downstream water use. A downstream country can acquire additional water from the upstream country, using non-water transfers. These transfers can be lump-sum payments, as in the 1960 Indus Waters Treaty (India, Pakistan). This treaty-allocating the east tributaries of the river to India and the west tributaries to Pakistan-included a one-time $£ 62$ million lump-sum payment by India (Beach et al. 2000). These transfers can also be annual payments, as in the Lesotho Highlands Water Project (Lesotho, South Africa). Under this treaty, South Africa pays non-water transfers to Lesotho, increasing from $€ 14$ million in 1998, when actual water deliveries started, to $€ 24$ million in 2004 (LHDA 2005). This example is exceptional because in most cases non-water transfers are constant over time.

Another possibility is the use of transfers in-kind. Monetary payments may be difficult from a political point of view or because the benefits from water are hard to monetise. In-kind transfers can be achieved by linking water transfers to other issues, that provide a benefit to 
the upstream country. For example, the Netherlands linked the issue of water allocation in the Meuse river to the issue of navigation on the Scheldt river. The Netherlands would gain from the water allocation treaty, while Belgium would gain from the improved access to the Antwerp harbour. Eventually, the agreement on water allocation in the Meuse was linked to the routing of an international railway track (Mostert 2003).

There exist many water allocation agreements where non-water transfers are not part of the agreement, for various reasons. In the Nile basin, for instance, the military threat posed by Egypt plays an important role for the absence of non-water transfers. This threat can, nevertheless, be considered as equivalent to a non-water transfer (cf. Janmaat and Ruijs 2006). Another possible reason is that the countries involved recognise historical water use or the equitable use of a shared resource.

\subsection{Reactions to Noncompliance}

In principle, an upstream country can use any available water whenever it wants, without considering downstream water needs. History has shown that indeed upstream countries may do this. A famous example relates to India's construction of the Farakka barrage in the Ganges basin. After the construction, India extended its trial operation of the barrage throughout the 1975-1976 dry season, diverting water away from the Ganges and through the new canal at full capacity. This operation led to severe water shortages in Bangladesh (Beach et al. 2000). A second example relates to the partitioning of the Indian subcontinent in 1947. A dispute on water rights led India to divert all water supply away from Pakistan's irrigation canals in 1948 (Barrett 1994). A third example is Turkey diverting all the water from the Euphrates for a month to create a reservoir behind the newly constructed Atatürk Dam in 1990, depriving Syria and Iraq of water.

These examples show that ultimately the upstream country has the power over shared water resources. Water rights that are specified in a water allocation agreement cannot be enforced by a downstream country. Especially so, because there is no higher authority that can enforce compliance. In half of the current water allocation agreements disputes are managed by advisory councils, governments' conflict-addressing bodies, the United Nations, or other third parties (Wolf 1998). The other half of the agreements does not refer to any form of dispute resolution. The absence of a higher authority that can issue penalties is clear. As a result, the only reasonable reaction to upstream noncompliance is to stop or reduce any non-water transfers. This strategy can be most effective when the issue of water allocation is linked to another transboundary issue between the two countries (Folmer et al. 1993).

In addition to a possible reduction of non-water transfers, noncompliance is likely to lead to a temporary pause of the agreement and requests for international mediation. Examples of this situation have occurred for instance in the Indus and Euphrates basins. After India diverted water away from Pakistan's irrigation canals in 1948, breaking the 1947 "Standstill Agreement", four years passed before renegotiations began. Another eight years later and with considerable support from the World Bank, disagreement was settled and the 1960 Indus Waters Treaty was signed (Beach et al. 2000). In the Euphrates basin, the 1987 security protocol between Turkey and Syria guaranteed Syria an annual average minimum flow of 500 cubic meters per second. In return, Syria would cooperate in security matters, related to its support to the Kurdish Workers' Party in Turkey. The agreement did not last long as Turkey continued the construction of a large-scale irrigation project, and Syria did not keep to its promise. Follow-up agreements in 1992 and 1993 failed for the same reason. 


\section{A Model of Cooperation}

Based on the examples presented in Sect. 2, we construct a two-country model of cooperation. A river is shared by two countries $i \in\{u, d\}$, having its source in the upstream country $u$ and subsequently flowing through the downstream country $d . Q_{t}$ denotes the volume of river flow in year $t$ that is available for use; it excludes the river flow necessary to sustain the environmental functioning of the river system and other vital services such as navigation. $Q_{t}$ is defined by probability density function $f(Q)$ (cf. Krzysztofowicz 2001). Contributions to river flow in $d$ are negligible as are return flows. Climate change effects on river flow are included in the model by adapting the probability density function from $f(Q)$ to $f^{\prime}(Q)$.

In year $t$, country $i$ uses $q_{i, t}$ units of water. Because of the unidirectional flow of water, $u$ has the first option to use water, which may limit water use by $d$. All water that was not used by $u$, is available for use by $d$ :

$$
\begin{gathered}
0 \leq q_{u, t} \leq Q_{t} \\
0 \leq q_{d, t} \leq Q_{t}-q_{u, t}
\end{gathered}
$$

Benefits $B_{i, t}\left(q_{i, t}\right)$ from water use are increasing and concave with a maximum at $\bar{q}_{i, t}$. Clearly, if $u$ maximises benefits of water use, it does not have an incentive to pass water to $d$ that has a positive marginal value to him. Yet, if the benefit to $d$ of using more water outweighs the decrease in benefits to $u$, there is scope for cooperation, with $u$ passing on water to $d$, in exchange for non-water transfers. Because we are interested in such situations, we assume water scarcity such that $\bar{q}_{u, t}+\bar{q}_{d, t} \geq E\left(Q_{t}\right)$. When the possible gains from cooperation are fully captured, the water allocation is Pareto-efficient. More specifically, a water allocation $\left(q_{u, t}^{\star}, q_{d, t}^{\star}\right)$ is Pareto-efficient for $Q_{t}$, when $B_{u, t}\left(q_{u, t}^{\star}\right)+B_{d, t}\left(q_{d, t}^{\star}\right) \geq$ $B_{u, t}\left(q_{u, t}\right)+B_{d, t}\left(q_{d, t}\right) \forall\left(q_{u, t}, q_{d, t}\right)$. An efficient agreement, however, is not necessarily stable, as will be illustrated in Sect. 6.

We analyse three basic sharing rules:

Proportional allocation (PA): $u$ receives $\alpha Q_{t}$ and $d$ receives $(1-\alpha) Q_{t}$, with $0<\alpha<1$;

Fixed upstream allocation (FU): $u$ receives $\min \left\{\beta, Q_{t}\right\}$ and $d$ receives $\max \left\{Q_{t}-\beta, 0\right\}$, with $0<\beta<E\left(Q_{t}\right)$;

Fixed downstream allocation (FD): $u$ receives $\max \left\{Q_{t}-\gamma, 0\right\}$ and $d$ receives $\min \left\{\gamma, Q_{t}\right\}$, with $0<\gamma<E\left(Q_{t}\right)$.

Because of water scarcity and increasing and concave benefit functions, and because for each of these sharing rules we have that $q_{i, t}^{\prime} \geq q_{i, t}$ if $Q_{t}^{\prime}>Q_{t}$, we know that cooperation increases total benefits of water use:

$$
B_{u, t}^{c}+B_{d, t}^{c} \geq B_{u, t}^{n}+B_{d, t}^{n} \forall Q_{t}
$$

where superscript $c$ denotes cooperation, $n$ denotes non-cooperation, and water use-and therefore benefits-depends on the sharing rule agreed upon. Note that we use $B_{i, t}^{c}$ and $B_{i, t}^{n}$ as shorthand notation for $B_{i, t}\left(q_{i, t}^{c}\right)$ and $B_{i, t}\left(q_{i, t}^{n}\right)$. Cooperative benefits $B_{i, t}^{c}$ are determined by the use of one of the three sharing rules. Non-cooperative benefits $B_{i, t}^{n}$ are determined by unilateral benefit maximisation. That is, country i uses $q_{i, t}^{n}$ units of water such that $B_{i, t}^{n}$ is maximised, subject to constraints (1) and (2).

For cooperation to be attractive to $u$, we need to include non-water transfers $m_{t}^{c}$ paid by $d$ to $u$. These non-water transfers can be monetary (lump-sum or annual side payments), in-kind, 
or based on issue linking, as discussed in Sect. 2. Because of this diversity in possible nonwater transfers, we distinguish two general types of non-water transfers. Type $I$ - denoted by $m^{I}$ - has a constant value over time, representing non-water transfers that cannot be easily adjusted over time, such as issue linking. Type $I I$ —denoted by $m_{t}^{I I}$ - has a value that depends on $Q_{t}$, representing non-water transfers that can be easily adjusted to river flow in year $t$, such as monetary transfers. We assume that non-water transfers are equal to the value of compensation of $u$ for benefits foregone and a share $\epsilon$ of the additional benefits from cooperation. The two types of non-water transfers, paid by $d$ to $u$, are calculated as:

$$
\begin{aligned}
m^{I} & =E\left(B_{u, t}^{n}-B_{u, t}^{c}+\epsilon\left[\left(B_{d, t}^{c}+B_{u, t}^{c}\right)-\left(B_{d, t}^{n}+B_{u, t}^{n}\right)\right]\right) \\
m_{t}^{I I} & =B_{u, t}^{n}-B_{u, t}^{c}+\epsilon\left[\left(B_{d, t}^{c}+B_{u, t}^{c}\right)-\left(B_{d, t}^{n}+B_{u, t}^{n}\right)\right]
\end{aligned}
$$

with $0 \leq \epsilon \leq 1$ and $E\left(m^{I}\right)=E\left(m_{t}^{I I}\right)$. As can be seen from Eqs. 4 and 5, the only difference between $m^{I}$ and $m_{t}^{I I}$ is that $m^{I}$ is calculated based on expected water use instead of current water use. Therefore, $m^{I}$ is constant while $m_{t}^{I I}$ adjusts to river flow in year $t$.

This method to calculate non-water transfers is commonly used in the literature on international environmental agreements. Chander and Tulkens (1997), for instance, show that correctly designed side payments - resembling those in Eqs. 4 and 5-can stabilise international environmental agreements in a setting of uniformly mixing pollutants. This method is also related to the Nash bargaining solution; a common solution concept from non-cooperative game theory. The Nash bargaining solution of a game maximises $\left(x_{u}-z_{u}\right)\left(x_{d}-z_{d}\right)$, subject to $\left(x_{u}, x_{d}\right) \in F$, where $F$ is the feasible set of payoff vectors and $\left(z_{u}, z_{d}\right)$ are non-cooperative payoffs (cf. Osborne and Rubinstein 1994). Here, the non-water transfers are calculated according to the asymmetric Nash bargaining solution. ${ }^{1}$

We analyse the stability of cooperation using an infinitely repeated game-a common approach in the analysis of international environmental agreements (cf. Finus 2002) - because water allocation agreements typically do not have a specified termination date. The stage game in year $t$ is played as follows. First, a value of $Q_{t}$ is realised from its probability distribution and observed by the countries. Second, $u$ chooses $q_{u, t}$. If complying with the agreement, $u$ plays $q_{u, t}=q_{u, t}^{c}$ according to the selected sharing rule. If not complying, $u$ plays $q_{u, t}=q_{u, t}^{n}=\min \left\{\bar{q}_{u, t}, Q_{t}\right\}$. Third, $d$ observes $u$ 's action and chooses $m_{t}$. If complying with the agreement, $d$ plays $m_{t}=m_{t}^{c}$ (which equals $m^{I}$ or $m_{t}^{I I}$, as specified in the agreement). If not complying, $d$ plays $m_{t}=m_{t}^{n}=0$. Fourth, countries observe the strategy played by the other country and receive payoffs.

The decision to comply or not comply in year $t$ is based on the expected payoff stream: $E\left(\Pi_{i, t}\right)=\max \left(E\left(\Pi_{i, t}^{c}\right), E\left(\Pi_{i, t}^{n}\right)\right)$. We re-interpret the common reactions to noncompliance discussed in Sect. 2 to punishment strategies. We assume that both countries use a trigger strategy: when a country is not complying, it is punished by the other country in the form of $p$ years non-cooperative play of the stage game, after which countries expect to return to cooperative play (i.e. agreement strategies). The type of punishment used here differs from Bennett and Howe (1998), who used monetary penalties in their analysis of cooperation between US states. Based on the examples presented in Sect. 2, we assume here that there is no authority that can issue such penalties in case of noncompliance. The expected payoff streams to $u$ and $d$ for compliance in year $t$ equal:

1 Two alternative methods to calculate non-water transfers are the Shapley value and Nucleolus, solution concepts from cooperative game theory. 


$$
\begin{aligned}
& E\left(\Pi_{u, t}^{c}\right)=B_{u, t}^{c}+m^{c}+\sum_{\tau=t+1}^{\infty} \delta^{\tau-t}\left[E\left(B_{u, \tau}^{c}\right)+E\left(m_{\tau}^{c}\right)\right] \\
& E\left(\Pi_{d, t}^{c}\right)=B_{d, t}^{c}-m^{c}+\sum_{\tau=t+1}^{\infty} \delta^{\tau-t}\left[E\left(B_{d, \tau}^{c}\right)-E\left(m_{\tau}^{c}\right)\right]
\end{aligned}
$$

where $\delta$ is the discount factor. The expected payoff streams to $u$ and $d$ for noncompliance in year $t$ equal:

$$
\begin{aligned}
& E\left(\Pi_{u, t}^{n}\right)=B_{u, t}^{n}+\sum_{\tau=t+1}^{t+p} \delta^{\tau-t}\left[E\left(B_{u, \tau}^{n}\right)\right]+\sum_{\tau=t+p+1}^{\infty} \delta^{\tau-t}\left[E\left(B_{u, \tau}^{c}\right)+E\left(m_{\tau}^{c}\right)\right] \\
& E\left(\Pi_{d, t}^{n}\right)=B_{d, t}^{c}+\sum_{\tau=t+1}^{t+p} \delta^{\tau-t}\left[E\left(B_{d, \tau}^{n}\right)\right]+\sum_{\tau=t+p+1}^{\infty} \delta^{\tau-t}\left[E\left(B_{d, \tau}^{c}\right)-E\left(m_{\tau}^{c}\right)\right]
\end{aligned}
$$

The differences, $D_{u}$ and $D_{d}$, equal the increase in expected payoffs due to noncompliance by $u$ or $d:^{2}$

$$
\begin{aligned}
& D_{u}=B_{u, t}^{n}-B_{u, t}^{c}-m^{c}+\sum_{\tau=t+1}^{t+p} \delta^{\tau-t}\left[E\left(B_{u, \tau}^{n}\right)-E\left(B_{u, \tau}^{c}\right)-E\left(m_{\tau}^{c}\right)\right] \\
& D_{d}=m^{c}+\sum_{\tau=t+1}^{t+p} \delta^{\tau-t}\left[E\left(B_{d, \tau}^{n}\right)-E\left(B_{d, \tau}^{c}\right)+E\left(m_{\tau}^{c}\right)\right]
\end{aligned}
$$

Positive values of $D_{i}$ imply that country $i$ has an incentive to deviate from the agreement. Substituting Eqs. 4 and 5 into Eqs. 10 and 11, we can derive $D_{u}$ and $D_{d}$ for the two types of transfers, see the Appendix. For type $I$ transfers, $D_{d}$ is independent from the level of $Q_{t}$ and therefore constant for a given probability distribution of $Q$. Because an agreement would not be signed if $D_{d} \geq 0$ at the expected value of river flow, we consider only those situations where $D_{d}$ is negative for any $Q_{t}$. Therefore, $d$ will never have an incentive to deviate from the agreement.

For type $I I$ transfers, $D_{u}$ depends on a share of non-cooperative benefits minus cooperative benefits at current river flow plus the negative punishment term. Because cooperation is attractive-see Eq. 3-we know that $D_{u}<0$, which implies that $u$ will never have an incentive to deviate from the agreement.

Concluding this section, the type of transfers that is used has implications for countries' incentives to comply with the agreement. With type $I$ (constant) transfers, $d$ never has an incentive to deviate from the agreement, but $u$ may deviate if gains from non-cooperation outweigh the fixed transfer. With type $I I$ (flexible) transfers, $u$ never has an incentive to deviate from the agreement, but $d$ may deviate if the transfer outweighs its foregone benefits in the punishment period. In the next section, we will assess the stability of cooperation with climate change effects and different sharing rules.

\footnotetext{
${ }^{2}$ Note that we calculate $D_{d}$ assuming that $u$ complies with the agreement. Because we are primarily interested in the stability of the agreement - and not payoffs or efficiency-it is irrelevant which of the two countries deviates in a certain year. Any anticipated noncompliance by $u$ (because it expects $d$ to not comply in that year) does therefore not affect the results.
} 


\section{Analysing Stability}

The folk theorem tells us that cooperation can be sustained in equilibrium as long as punishments are severe enough. When discounted payoffs of cooperation outweigh the sum of discounted payoffs of noncompliance in one year and Nash-payoffs during the subsequent punishment phase, an agreement is stable in that particular year.

Because of the uncertainty of payoffs in our model, through the stochastic variable $Q$, it is not possible to assess whether cooperation is stable or not. It is, however, possible to assess the probability of stability. To do this, we need to determine values of $Q_{t}$ for which the agreement is not stable in year $t$; i.e. where either $D_{u} \geq 0$ or $D_{d} \geq 0$. Let the set $\hat{Q} \subset Q$ contain these values. We know that $\hat{Q}$ is a proper subset of $Q$, because an agreement would not be signed if $D_{u} \geq 0$ or $D_{d} \geq 0$ at the expected value of river flow. Therefore $E\left(Q_{t}\right) \notin \hat{Q}$. Because benefit functions $B_{i, t}\left(q_{i, t}\right)$ are increasing and concave (see Sect. 3), we can derive some properties of $D_{u}$ and $D_{d}$ that help to specify $\hat{Q}$ further, using Eqs. 10 and 11 and the fact that $q_{u, t}^{n} \geq q_{u, t}^{c}$. In case of type $I$ transfers, $D_{u}$ is a single-peaked function of $Q_{t}$, and $D_{d}$ has a constant negative value. In case of type $I I$ transfers, $D_{d}$ is a single-peaked function of $Q_{t}$, and $D_{u}$ is always negative. This implies that, for both type $I$ and $I I$ transfers, $\hat{Q}$ is a continuous set. Because $\hat{Q}$ is a continuous set, and because we focus on water scarcity, we assume that $Q_{t}<E\left(Q_{t}\right) \forall Q_{t} \in \hat{Q}$. This assumption is based on the idea that scarcity is the cause of instability of water allocation agreements, as discussed in Sect. 2.

Having specified $\hat{Q}$, we can express the probability of stability as $\operatorname{Pr}\left[Q_{t} \notin \hat{Q}\right]$. Given that $f(Q)$ is the probability density function of $Q$, we can calculate $\operatorname{Pr}\left[Q_{t} \notin \hat{Q}\right]$ as the area under $f(Q)$ where $Q_{t} \notin \hat{Q}$. Denote lower and upper bounds of $\hat{Q}$ by $\hat{Q}^{-}$and $\hat{Q}^{+}$, then the probability of stability of an agreement equals:

$$
\operatorname{Pr}\left[Q_{t} \notin \hat{Q}\right]=1-\int_{\hat{Q}^{-}}^{\hat{Q}^{+}} f(Q) d Q
$$

Equation (12) is illustrated in Fig. 1. In the remainder of this paper we will use this expression as our stability indicator and refer to it simply as "stability".

We are interested in probability density functions of $Q$ without and with climate change. A comparison of the stability in each situation shows how climate change affects the stability of cooperation. Because $\hat{Q}^{-}$and $\hat{Q}^{+}$are constant (i.e. independent from $f(Q)$ ), we can compare stability of an agreement for $f(Q)$ (no climate change) and $f^{\prime}(Q)$ (climate change). Stability in a situation with climate change is lower when it decreases $\operatorname{Pr}\left[Q_{t} \notin \hat{Q}\right]$, increasing the size of the shaded area in Fig. 1. Climate change is expected to affect river flow through the combined effects of changes in temperature, evaporation, soil moisture, and precipitation. Two general results of climate simulation models are (i) increased runoff variability, both within seasons and within years, and (ii) an increase of river flow in cold river basins and a decrease in warmer regions (cf. Arnell 1999; Räisänen et al. 2004; IPCC 2007a). For the probability distribution of $Q$ this implies a change in the mean river flow and an increased variance of river flow.

Note that climate change effects do not affect stability if $\hat{Q}=\emptyset$. If an agreement is stable for $f(Q)$, it is stable for any $f^{\prime}(Q) \neq f(Q)$. If $\hat{Q} \neq \emptyset$, climate change effects on stability depend on whether they affect the size of the shaded area in Fig. 1. Note that the exact location and size of this shaded area depend on whether type $I$ or type $I I$ transfers are used.

Recall that we assume $Q_{t}<E\left(Q_{t}\right) \forall Q_{t} \in \hat{Q}$. Clearly, the functional form of $f(Q)$ has implications for climate change effects on stability. Commonly applied distributions in the literature on probabilistic hydrological forecasting include the gamma and (log-) normal 


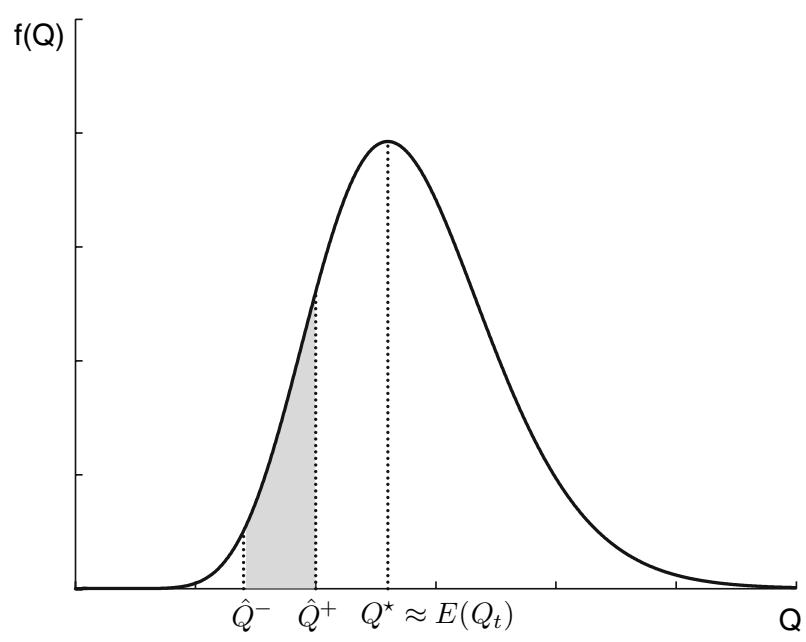

Fig. 1 An example of a (gamma) probability density function for $Q_{t}$. Stability is calculated according to Eq. 12; it equals the area under $f(Q)$ excluding the shaded area

distributions (cf. Bobee and Ashkar 1991). In a survey of close to 1000 sites worldwide, Finlayson and McMahon (1992) found that the annual streamflow of about $60 \%$ of these sites can be approximated by the normal distribution. This implies that $f(Q)$ is continuous, increasing up to $E\left(Q_{t}\right)$, and symmetric by approximation (Fig. 1 depicts a gamma distribution that is approximately symmetric).

An increased variance of river flow implies that more weight is given to the tails of the probability density function. The effect of increased variance therefore depends on the size and location of $\hat{Q}$. The only information on the lower and upper bounds of $\hat{Q}$ we have is that $\hat{Q}^{-} \leq \hat{Q}^{+}<E\left(Q_{t}\right)$. The size and location of $\hat{Q}$ are bounded only by the lowest value of $Q$ and $E\left(Q_{t}\right)$. Therefore, the effect of increased variance of river flow on stability can be positive or negative. If $\hat{Q}^{-}$is located close to the lowest value of $Q$, an increased variance is likely to increase the size of the shaded area and decrease stability. If $\hat{Q}^{+}$is located close to $E\left(Q_{t}\right)$, an increased variance is likely to decrease the size of the shaded area and increase stability.

Consider a decreasing mean river flow. Because of the properties of $f(Q)$, established above, a decreasing mean river flow will decreases stability as long as $f\left(\hat{Q}^{-}\right) \leq f\left(\hat{Q}^{+}\right)$, see Fig. 2. The reverse holds for increasing mean river flow. Because of symmetry of $f(Q)$, we know that $E\left(Q_{t}\right) \approx Q^{\star}$, where $Q^{\star}$ equals $Q$ for which $f(Q)$ is maximised, see Fig. 1. Therefore, we can generalise that $f\left(\hat{Q}^{-}\right) \leq f\left(\hat{Q}^{+}\right) \forall \hat{Q}$. Consequently, a decrease (increase) in mean river flow decreases (increases) stability. More formally, given the above observations we have:

$$
1-\int_{\hat{Q}^{-}}^{\hat{Q}^{+}} f(Q) d Q>1-\int_{\hat{Q}^{-}}^{\hat{Q}^{+}} f^{\prime}(Q) d Q \text { if } E\left(Q_{t}\right)\left|f(Q)>E\left(Q_{t}\right)\right| f^{\prime}(Q)
$$

This proofs the following result:

Result 1 Stability of a water allocation agreement depends on the probability density function of river flow. Stability decreases if mean river flow decreases. An increased variance can have a positive or a negative effect on stability. 


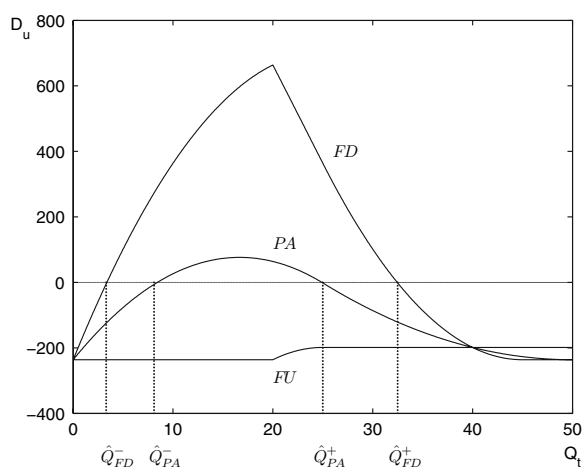

(a) $D_{u}$ for type $I$ transfers

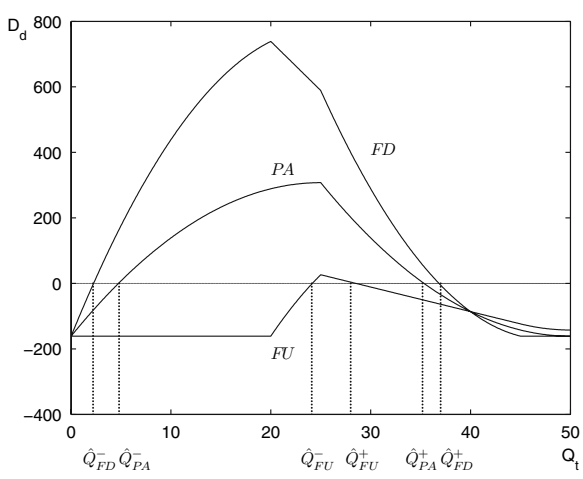

(b) $D_{d}$ for type $I I$ transfers

Fig. 2 The increase in expected payoffs due to noncompliance to $u$ and $d$, for different levels of $Q_{t}$ and different sharing rules

Note that this result holds for both types of transfers, although the size of the effect may be different.

We expect the stability of cooperation to be different for different sharing rules. To verify this expectation, we compare $\hat{Q}$ for the three sharing rules. In the comparison, we set $\alpha E\left(Q_{t}\right)=\beta=E\left(Q_{t}\right)-\gamma$, such that at $Q_{t}=E\left(Q_{t}\right)$ the water allocation is similar for each sharing rule. In calculating $\hat{Q}$ from Eqs. 10 and 11 we can ignore all constant elements, such as the punishment terms, because they are equal for all three sharing rules. Because we assume that all elements in $\hat{Q}$ lie below $E\left(Q_{t}\right)$, we only look at the situation where $Q_{t}<E\left(Q_{t}\right)$. Note that if $Q_{t}<E\left(Q_{t}\right)$, we have $Q_{t}-\gamma<\alpha Q_{t}<\beta$.

In case of type $I$ transfers, we use Eq. 10, from which we cancel all constant terms, which leaves the term $-B_{u, t}^{c}$ to be compared for the three sharing rules. For type $I$ transfers, we find that $D_{u}^{F D}>D_{u}^{P A}>D_{u}^{F U} \forall Q_{t}<E\left(Q_{t}\right)$. In case of type $I I$ transfers, we use Eq. 11, from which we cancel all constant terms, which leaves the term $\epsilon\left(B_{u, t}^{c}+B_{d, t}^{c}\right)-B_{u, t}^{c}$ to be compared for the three sharing rules. For type II transfers, we find that $D_{d}^{F D}>D_{d}^{P A}>$ $D_{d}^{F U} \forall Q_{t}<E\left(Q_{t}\right)$. Because both $D_{u}$ and $D_{d}$ are single-peaked, we have for both types of transfers:

$$
\hat{Q}^{F U} \subset \hat{Q}^{P A} \subset \hat{Q}^{F D}
$$

Because stability is defined according to Eq. 12, stability is highest for FU and lowest for FD. Formally, from Eqs. 12 and 14 we can construct:

$$
1-\int_{\hat{Q}_{F U}^{-}}^{\hat{Q}_{F U}^{+}} f(Q) d Q>1-\int_{\hat{Q}_{P A}^{-}}^{\hat{Q}_{P A}^{+}} f(Q) d Q>1-\int_{\hat{Q}_{F D}^{-}}^{\hat{Q}_{F D}^{+}} f(Q) d Q
$$

This proofs the following result:

Result 2 Stability of a water allocation agreement depends on the sharing rule. It is higher for fixed upstream allocation than for proportional allocation and lowest for fixed downstream allocation.

For type $I$ transfers, this result is a direct consequence of the amount of risk connected to low flows that is allocated to $u$. For FU, this risk is minimised as $u$ receives a fixed amount of water, constrained only by the amount of river flow available. For FD, this risk is maximised 
because if river flow decreases by one unit, the allocation to $u$ may also decrease by one unit. For PA, this risk lies somewhere between those of FU and FD.

For type $I I$ transfers, the intuition behind this result is that the transfer includes a compensation for benefits foregone to $u$. For $Q_{t}<E\left(Q_{t}\right)$, this compensation is higher for FD than for PA and lowest for FU. Because of the Stackelberg setting, $d$ first receives water and then decides whether or not to pay the transfer. The size of the transfer relative to the punishment term determines whether $d$ complies with the agreement. Clearly, incentives for noncompliance are higher for FD than for PA and lowest for FU.

Taking a closer look at FU with type $I$ transfers, we find that $u$ can never have an incentive to deviate from the agreement. To prove this result, we show that $D_{u}$ for type $I$ transfers-see Eq. 10 - is always negative for FU. First we find the value of $q_{u, t}$ for which $D_{u}$ is maximised. Note that we can ignore the punishment term and non-water transfers because they are constant, so we consider the maximisation problem $\max _{q u, t} B_{u, t}^{n}-B_{u, t}^{c}$. There are three possibilities:

1. if $Q_{t}<\beta<\bar{q}_{u, t}$ then $q_{u, t}^{n}=Q_{t}$ and $q_{u, t}^{c}=Q_{t}$;

2. if $\beta<Q_{t}<\bar{q}_{u, t}$ then $q_{u, t}^{n}=Q_{t}$ and $q_{u, t}^{c}=\beta$;

3. if $\bar{q}_{u, t} \leq Q_{t}$ then $q_{u, t}^{n}=\bar{q}_{u, t}$ and $q_{u, t}^{c}=\beta$.

Clearly, in the last situation, $B_{u, t}^{n}-B_{u, t}^{c}$ is maximised. We argue that the last situation includes $Q_{t}=E\left(Q_{t}\right)$, because we assume that $\bar{q}_{u, t} \leq E\left(Q_{t}\right)$. This assumption is based on the idea that in the short term, $u$ 's economy and infrastructure are not designed to abstract and use (much) more water than is expected in a given year. ${ }^{3}$ Because we may assume that $D_{u}<0$ and that $D_{u}$ is maximised for $Q_{t}=E\left(Q_{t}\right)$, we know that $D_{u}<0$ for any level of $Q_{t}$. It follows that $\hat{Q}=\emptyset$ for FU with type $I$ transfers. Hence $\operatorname{Pr}\left[Q_{t} \notin \hat{Q}\right]=1$; FU with type $I$ transfers is stable. This proofs the following result:

Result 3 Water allocation agreements with fixed upstream allocation and type $I$ transfers are stable for any level of river flow.

\section{Asymmetry}

In this section, we assess the effects on stability of asymmetry in political power and benefit functions. For both factors we assess how they affect stability before and after an agreement has been signed.

As described by LeMarquand (1977), the distribution of political power has implications for the incentives for cooperation. In our model we can incorporate this aspect through the level of $\epsilon$, which we define here to be a measure of political power for the upstream country. When benefit functions are symmetric, Kilgour and Dinar (2001) have shown that in an efficient situation, the surplus benefit is equally shared between the two countries; in our model this implies that $\epsilon=0.5$.

When $\epsilon<0.5, d$ has more political power than $u$ and therefore a stronger bargaining position. As a result, the non-water transfer from $d$ to $u$ is lower than in a situation with equally distributed political power. To assess the effect of political power on stability, we take the derivative of Eq. 10 for type $I$ transfers and (11) for type $I I$ transfers, with respect to $\epsilon$ :

${ }^{3}$ If $\bar{q}_{u, t} \gg E\left(Q_{t}\right), \mathrm{FU}$ is unstable for $Q_{t}$ large enough. 


$$
\begin{aligned}
\frac{\partial D_{u}}{\partial \epsilon}= & \sum_{\tau=t}^{t+p} \delta^{\tau-t} E\left[\left(B_{d, \tau}^{n}+B_{u, \tau}^{n}\right)-\left(B_{d, \tau}^{c}+B_{u, \tau}^{c}\right)\right]<0 \\
\frac{\partial D_{d}}{\partial \epsilon}= & \left(B_{d, t}^{c}+B_{u, t}^{c}\right)-\left(B_{d, t}^{n}+B_{u, t}^{n}\right) \\
& +\sum_{\tau=t+1}^{t+p} \delta^{\tau-t} E\left[\left(B_{d, \tau}^{c}+B_{u, \tau}^{c}\right)-\left(B_{d, \tau}^{n}+B_{u, \tau}^{n}\right)\right]>0
\end{aligned}
$$

Because of Eq. 3, Eq. 16 yields a negative and Eq. 17 yields a positive value. For type $I$ transfers, an increase of $\epsilon$ leads to a decrease of $D_{u}$, increasing the stability for each level of river flow. For type $I I$ transfers, an increase of $\epsilon$ leads to an increase of $D_{d}$, decreasing the stability for each level of river flow. This result holds for each sharing rule. The intuition behind this result is that when $\epsilon$ is high, the non-water transfer is high relative to benefits foregone to $u$, making cooperation more attractive to $u$ and less attractive to $d$.

For type $I$ transfers, changes in the distribution of political power after an agreement has been signed have no effect on stability because the effect of $\epsilon$ on $D_{u}$ works via $m^{I}$, which has been fixed. Of course, it is well possible that a change in political power leads to renegotiations of the terms of the agreement, with a more favourable outcome for the more powerful country. If the upstream country is the winner of these renegotiations, $\epsilon$ will increase, $D_{u}$ will decrease and the agreement will be more stable. If the downstream country is the winner of these renegotiations, $\epsilon$ will decrease, $D_{u}$ will increase and the agreement will be less stable.

Asymmetry in benefit functions between countries is assessed by scaling $u$ 's benefit function by a factor $\eta: B_{u, t}=\eta h\left(q_{u, t}\right)$ and $B_{d, t}=h\left(q_{d, t}\right)$. To assess the effect on stability for both types of transfers, we analyse how $\eta$ affects $D_{u}$ and $D_{d}$ by taking the derivatives of Eq. 10 for type $I$ transfers and Eq. 11 for type $I I$ transfers, with respect to $\eta$ :

$$
\begin{aligned}
\frac{\partial D_{u}}{\partial \eta}= & h\left(q_{u, \tau}^{n}\right)-h\left(q_{u, \tau}^{c}\right)+\sum_{\tau=t+1}^{t+p} \delta^{\tau-t} \epsilon\left[E\left[h\left(q_{u, \tau}^{n}\right)\right]-E\left[h\left(q_{u, \tau}^{c}\right)\right]\right]>0 \\
\frac{\partial D_{d}}{\partial \eta}= & (1-\epsilon)\left[h\left(q_{u, \tau}^{n}\right)-h\left(q_{u, \tau}^{c}\right)\right] \\
& +\sum_{\tau=t+1}^{t+p} \delta^{\tau-t}(1-\epsilon)\left[E\left[h\left(q_{u, \tau}^{n}\right)\right]-E\left[h\left(q_{u, \tau}^{c}\right)\right]\right]>0
\end{aligned}
$$

Equations 18 and 19 both yield positive values, because the non-cooperative benefits to $u$ outweigh the cooperative benefits, both at current and expected levels of river flow. An increase of $\eta$ leads to an increase of $D_{u}$ with type $I$ transfers and $D_{d}$ with type $I I$ transfers, decreasing the stability for each level of river flow. This result holds for each sharing rule. For any agreement, the higher the marginal benefits of water use to $u$ compared with those to $d$, the lower the stability of cooperation. The intuition behind this result is as follows. For type $I$ transfers, higher marginal benefits to $u$ increase its expected payoffs of noncompliance more than the transfer it receives from $d$. For type II transfers, higher marginal benefits to $u$ increase the transfer that $d$ has to pay to $u$, giving $d$ a higher incentive to deviate.

For type $I$ transfers, changes in $\eta$ after an agreement has been signed can also be calculated. Such a change may occur because of demographic or economic developments. This effect does not influence $m^{I}$, because $m^{I}$ has been fixed in the agreement. Therefore, to assess the effect on stability, we analyse how $\eta$ affects $D_{u}$ by taking the derivative of Eq. 10 with respect to $\eta$, similar to Eq. 18, but assuming that $m^{I}$ is fixed: 


$$
\frac{\partial m^{I}}{\partial \eta}=0
$$

Combining Eqs. 18 and 20 gives:

$$
\frac{\partial D_{u}}{\partial \eta}=h\left(q_{u, \tau}^{n}\right)-h\left(q_{u, \tau}^{c}\right)+\sum_{\tau=t+1}^{t+p} \delta^{\tau-t}\left[E\left[h\left(q_{u, \tau}^{n}\right)\right]-E\left[h\left(q_{u, \tau}^{c}\right)\right]\right]>0
$$

Equation 21 yields a positive value. For type $I$ transfers, an increase of $\eta$ after an agreement has been signed leads to an increase of $D_{u}$, decreasing the stability for each level of river flow. This result holds for each sharing rule. For any agreement, if marginal benefits to $u$ increase after the agreement has been signed, the stability of cooperation decreases.

The results of this section are summarised in result 4. Given derivatives (16)-(19) and (21), a positive sign of the derivative indicates an upward shift of the $D_{u}$ or $D_{d}$ curve, see Eqs. 10 and 11. Because these curves are single-peaked, an upward shift of the $D_{u}$ or $D_{d}$ curve decreases $\hat{Q}^{-}$and increases $\hat{Q}^{+}$, which decreases the stability indicator $1-\int_{\hat{Q}^{-}}^{\hat{Q}^{+}} f(Q) d Q$. This proofs the following result:

Result 4 Stability of a water allocation agreement depends on the level of symmetry of the countries. For type $I$ (type $I$ ) transfers, stability is higher (lower) when the upstream county has more political power. For both types of transfers, stability is higher when the upstream country has lower benefits of water use than the downstream country.

\section{Numerical Example}

To illustrate model results $1-3$, we use the following numerical example:

$$
\begin{array}{rlrl}
B_{i, t} & =75 q_{i, t}-1.5 q_{i, t}^{2} & E\left(Q_{t}\right) & =40 \\
\delta & =0.95 & \alpha & =0.5 \\
p & =5 & \beta & =20 \\
\epsilon & =0.5 & \gamma & =20
\end{array}
$$

The values for $\alpha, \beta$, and $\gamma$ are chosen such that at $Q_{t}=E\left(Q_{t}\right)$ the water allocation is similar for each sharing rule. Because the countries have identical benefit functions, the allocation is optimal when $Q_{t}=E\left(Q_{t}\right) .{ }^{4}$ Furthermore, for each sharing rule, cooperation is attractive to both countries for $Q_{t}=E\left(Q_{t}\right)$, because countries would never agree to cooperate if there was no expected gain from cooperation.

Figure 2 plots $D_{u}$ and $D_{d}$ for different levels of $Q_{t}$, for the three sharing rules. For both sub-figures, we observe that the size of $\hat{Q}$ for the three sharing rules is according to Eq. 14. Corresponding to results 2 and 3, the incentive to deviate is highest for FD and lowest for FU. Figure 2 shows that efficiency does not guarantee stability. Because the countries have identical benefit functions, PA provides a Pareto-efficient water allocation for each level of $Q_{t}$. Nevertheless, Fig. 2 shows that this efficient allocation is not always stable. The reason for the decrease in $D_{u}$ and $D_{d}$ for $Q_{t}$ less than \pm 20 is the decreasing gain of noncompliance relative to the punishment.

\footnotetext{
4 Because the countries have identical benefit functions in this example, PA will provide a more efficient allocation than FU or FD when climate change effects occur: the total benefits of water use are maximised. This property of the model is similar to results from efficiency studies that were surveyed in the introductory section of this paper (cf. Bennett et al. 2000).
} 


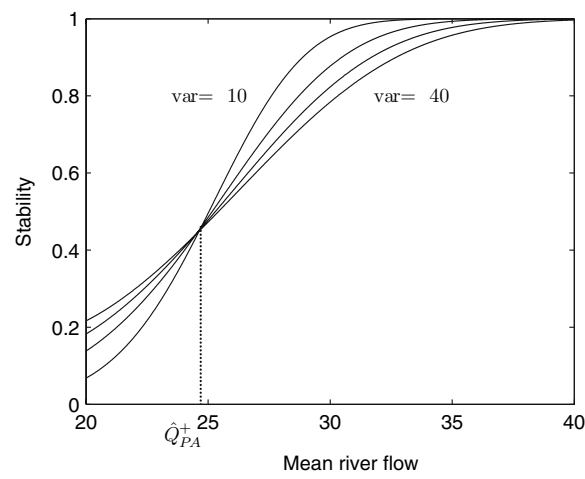

(a) Type $I$ transfers, $u$ might deviate

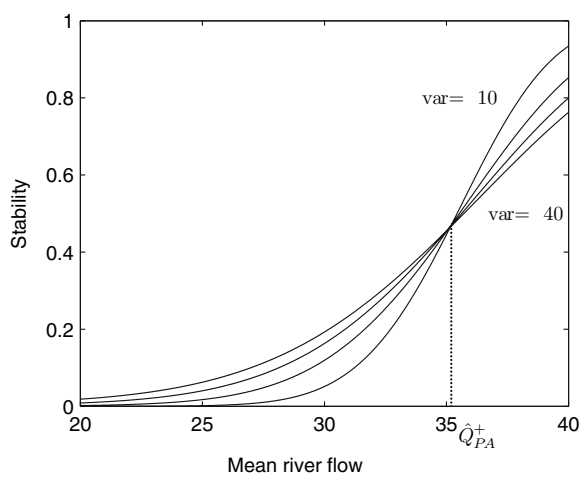

(b) Type II transfers, $d$ might deviate

Fig. 3 Stability $-\operatorname{Pr}\left[Q_{t} \notin \hat{Q}\right]$ —of an agreement with a PA sharing rule when climate change affects the mean river flow or the variance of river flow. Mean and variance are based on $f^{\prime}(Q)$, the probability density function of $Q_{t}$ when climate change effects occur. Similar graphs can be derived for FU and FD, the only difference being a horizontal shift of the curves

The stability of cooperation depends on the probability distribution of $Q$. In this example we use an (approximately symmetric) gamma distribution to describe $f(Q)$ and $f^{\prime}(Q)$. The effect of a change in the mean or variance of river flow on the stability of cooperation is shown in Fig. 3, for PA and both types of transfers. The mean river flow refers to the mean of $f^{\prime}(Q)$, the probability density function of $Q_{t}$ when climate change effects occur. ${ }^{5}$

Figure 3 illustrates result 1: a decrease in mean river flow decreases stability. When mean river flow decreases beyond $\hat{Q}^{+}$, the effect of changes in variance switches sign, illustrating that an increase in variance can have positive or negative effects on stability. Note that the fact that type $I$ transfers are more stable than type $I I$ transfers is due to this specific numerical example.

\section{Discussion}

The analysis presented here shows that climate change affects the stability of water allocation agreements. The precise effect on stability depends on (i) the characteristics of the river basin: its hydrological regime and the effects of climate change on river flow, and (ii) the characteristics of the agreement: in particular the sharing rule, the type of non-water transfers, the countries' benefit functions, and the distribution of political power. Because the results show that stability decreases when water becomes more scarce, this result is mostly relevant for arid regions. It is less relevant for humid regions and not relevant for regions facing (only) water quality issues: the impact of climate change on water quality is too complicated in hydrological terms to be captured in a simple model as the one presented here.

Mendelsohn and Bennett (1997) find that the impact of climate change on the mean river flow is a far more important determinant for efficiency than its impact on the variance of river

5 The calculation of expected benefits is still based on $E(Q)=40$ - the mean of the original probability density function $f(Q)$-because the agreement will not be immediately adapted at the first signs of climate change effects on river flow. Governments need reliable information before they are willing to change conditions of this type of agreements; long-term observations are needed before a change in the probability distribution of river flow can be assessed. Note that a change in river flow that results in a mean below 20 is not included in Fig. 3. For this type of extreme changes in mean river flow it would not be realistic to assume that the expected level of river flow remains $E\left(Q_{t}\right)=40$. 
flow. Our model suggests that this conclusion may not hold for the stability of cooperation. Stability is affected by changes in both mean and variance of river flow, so both have to be taken into account when negotiating agreements on water allocation.

Besides economic gain, there are other issues that influence the allocation of water to riparian countries and the stability of cooperation. First, as the example of the Nile river basin points out, acquired water rights can be an important determinant in the allocation of river water. A sharing rule based on acquired rights is not expected to be optimal from the points of view of efficiency and stability. Second, risk aversion might play a role. A country receiving a fixed allocation faces a lower risk of flow variability than a country that receives a non-fixed allocation or a proportional allocation (cf. Bennett et al. 2000). More risk-averse countries will prefer fixed allocations over proportional allocations. We expect stability to be positively affected by risk aversion as risk averse countries would appraise the certitude of cooperative benefits above non-cooperative benefits more than risk neutral countries.

Two approaches could be used to decrease the risk associated with low flows and generate more stable agreements. First, both $u$ and $d$ could decide to invest in reservoir capacity. When managed properly, reservoirs can provide a buffer in water supply, decreasing the dependency on river water in low flow years (Janmaat and Ruijs 2007). Second, a water allocation agreement can be extended with water trading, which could increase stability (cf. Booker and Young 1994). Water markets can improve the efficiency of existing water allocations such that both countries benefit. Both approaches reduce the incentive to break an existing agreement.

In theory, the use of punishment strategies enhances cooperation in a repeated game. In our model, however, punishment decreases payoffs of both the punished and the punishing country, because the non-cooperative outcome gives the punishing country lower payoffs than the cooperative outcome. Shortening the punishment period is therefore always beneficial to the punishing country. This undermines its credibility of actually going to punish in case of noncompliance. A lack of credibility of punishment strategies can obstruct the effective use of punishment strategies in international agreements on water allocation (Carraro et al. 2005). The examples in Sect. 2, however, show that this type of behaviour is not common. Moreover, the punishment period can be used by the harmed country to gain international support in the dispute over water, which can strengthen its bargaining position in renegotiations. Ideally, punishment is implemented in a linked game, which does not affect the benefits of the punishing country.

\section{Conclusions}

The objective of this paper is to assess the stability of water allocation agreements when climate change affects river flow. A game theoretic model is constructed that analyses the stability of cooperation in water allocation between two countries for three sharing rules. The stability of cooperation is expressed in terms of the probability that one of the two countries does not comply with the specified agreement actions, given that the countries maximise their expected payoff stream (consisting of benefits of water use and non-water transfers).

For each sharing rule, deviation from agreement actions is found unattractive to the downstream country $(d)$ with constant transfers and unattractive to the upstream country $(u)$ with flexible transfers. The stability of agreements depends on the probability distribution of $Q$. Our results show that a decrease in mean river flow decreases the stability of cooperation. An increased variance can have a positive or a negative effect on stability. Of the three sharing rules that were analysed, agreements with FU are more stable than those with PA and FD, 
for both constant and flexible transfers. With constant transfers, FU was found stable for any level of river flow.

In addition to the probability distribution of river flow and the sharing rule, three other factors are identified to affect stability of cooperation. The stability of cooperation is higher if the absolute value of the punishment term is higher, and if $u$ 's benefits of water use are low relative to $d$ 's benefits. If $u$ 's political power is large relative to $d$ 's political power, stability is higher for constant transfers, but lower for flexible transfers.

This paper shows that the stability of water allocation agreements can be affected by climate change. This paper adds to the analysis of water allocation agreements by focusing on stability aspects, where others have focused on efficiency aspects. Where Bennett et al. (2000) found that proportional allocations are more efficient in many situations, we find that proportional allocations are less stable than fixed upstream allocations. Where Mendelsohn and Bennett (1997) found that the largest impact of climate change on efficiency comes from changes in the mean river flow, we find that both changes in mean and variance affect stability. Because water allocation agreements need to be stable in order to increase the efficiency of water use, the results of this paper are important for the design of water allocation agreements and especially the selection of a sharing rule.

Acknowledgements We thank Joel Bruneau, Hans-Peter Weikard and two reviewers for valuable comments, and we acknowledge financial support by the European Union FP6 Integrated Project AquaTerra (project no. GOCE 505428).

Open Access This article is distributed under the terms of the Creative Commons Attribution Noncommercial License which permits any noncommercial use, distribution, and reproduction in any medium, provided the original author(s) and source are credited.

\section{Appendix}

Substituting Eq. 4 into Eq. 10 for type $I$ transfers yields:

$$
\begin{aligned}
& D_{u}=\underbrace{B_{u, t}^{n}-B_{u, t}^{c}}_{\geq 0} \underbrace{-E\left(B_{u, t}^{n}\right)+E\left(B_{u, t}^{c}\right)}_{\leq 0} \\
& \underbrace{-\sum_{\tau=t}^{t+p} \delta^{\tau-t} \epsilon\left[E\left(B_{d, \tau}^{c}\right)+E\left(B_{u, \tau}^{c}\right)-E\left(B_{d, \tau}^{n}\right)-E\left(B_{u, \tau}^{n}\right)\right]}_{\leq 0} \\
& D_{d}=\underbrace{E\left(B_{u, t}^{n}\right)-E\left(B_{u, t}^{c}\right)}_{\geq 0} \\
& \underbrace{+\left[E\left(B_{d, t}^{c}\right)+E\left(B_{u, t}^{c}\right)-E\left(B_{d, t}^{n}\right)-E\left(B_{u, t}^{n}\right)\right]}_{\geq 0} \underbrace{\left(\epsilon+(\epsilon-1) \sum_{\tau=t+1}^{t+p} \delta^{\tau-t}\right)}_{\sum_{0}}
\end{aligned}
$$

with $\epsilon$ and $p$ such that $D_{d}<0$ at $E\left(Q_{t}\right)$.

Substituting Eq. 5 into Eq. 11 for type $I I$ transfers yields:

$$
D_{u}=\underbrace{\epsilon\left[\left(B_{d, t}^{n}+B_{u, t}^{n}\right)-\left(B_{d, t}^{c}+B_{u, t}^{c}\right)\right]}_{\leq 0}
$$




$$
\begin{gathered}
+\underbrace{+\sum_{\tau=t+1}^{t+p} \delta^{\tau-t}(1-\epsilon)\left[E\left(B_{u, \tau}^{n}\right)+E\left(B_{d, \tau}^{n}\right)-E\left(B_{u, \tau}^{c}\right)-E\left(B_{d, \tau}^{c}\right)\right]}_{\leq 0} \\
D_{d}=\underbrace{B_{u, t}^{n}-B_{u, t}^{c}}_{\geq 0} \underbrace{+\epsilon\left[B_{u, t}^{c}+B_{d, t}^{c}-B_{u, t}^{n}-B_{d, t}^{n}\right]}_{\leq 0} \\
+\underbrace{\sum_{\tau=t+1}^{t+p} \delta^{\tau-t}(1-\epsilon)\left[E\left(B_{u, \tau}^{n}\right)+E\left(B_{d, \tau}^{n}\right)-E\left(B_{u, \tau}^{c}\right)-E\left(B_{d, \tau}^{c}\right)\right]}_{\geq 0}
\end{gathered}
$$

\section{References}

Ambec S, Sprumont Y (2002) Sharing a river. J Econ Theory 107(2):453-462

Arnell NW (1999) The effect of climate change on hydrological regimes in Europe: a continental perspective. Glob Environ Change 9(1):5-23

Barrett S (1994) Conflict and cooperation in managing international water resources. World Bank Policy Research Working Paper 1303

Beach HL, Hammer J, Hewitt JJ, Kaufman E, Kurki A, Oppenheimer JA, Wolf AT (2000) Transboundary freshwater dispute resolution: theory, practice, and annotated references. United Nations University Press, Tokyo, Japan

Bennett LL, Howe CW (1998) The interstate river compact: incentives for noncompliance. Water Resour Res 34(3):485-495

Bennett LL, Howe CW, Shope J (2000) The interstate river compact as a water allocation mechanism: efficiency aspects. Am J Agricult Econ 82(4):1006-1015

Bobee B, Ashkar F, (1991) The gamma family and derived distributions applied in hydrology. Water Resources Publications, Littleton, Colorado

Booker J, Young R (1994) Modeling intrastate and interstate markets for Colorado river water resources. J Environ Econ Manage 26(1):66-87

Carraro C, Marchiori C, Sgobbi A (2005) Applications of negotiation theory to water issues. FEEM Working Paper 65

Chalecki EL, Gleick PH (1999) A framework of ordered climate effects on water resources: a comprehensive bibliography. J Am Water Resour Assoc 35(6):1657-1665

Chander P, Tulkens H (1997) The core of an economy with multilateral environmental externalities. Int J Game Theory 26(3):379-401

Dinar A, Rosegrant MW, Meinzen-Dick R (1997) Water allocation mechanisms: principles and examples. World Bank Policy Research Working Paper 1779

Finlayson BL, McMahon TA (1992) Global runoff, encyclopedia of earth system science, vol 2. Academic Press, Inc, San Diego, CA

Finus M (2002) Game theory and international environmental cooperation: any practical application?. In: Bohringer C, Finus M, Vogt C (eds) Controlling global warming: perspectives from economics, game theory and public choice. Edward Elgar, Cheltenham, UK

Folmer H, Mouche P, Ragland S (1993) Interconnected games and international environmental problems. Environ Resour Econ 3(4):313-335

Giordano MA, Wolf AT (2003) Sharing waters: post-Rio international water management. Nat Resour Forum 27(2):163-171

Heintzelman MD (2004) Thirsty dogs: bargaining over interstate rivers. Canadian resource and environmental economics study group, 14th Annual Meeting

IPCC (2007a) Climate change 2007: impacts, adaptation, and vulnerability, contribution of working group II to the fourth assessment report of the intergovernmental panel on climate change. Cambridge University Press, Cambridge

IPCC (2007b) Climate change 2007: the physical science basis, contribution of working group I to the fourth assessment report of the intergovernmental panel on climate change. Cambridge University Press, Cambridge 
Janmaat J, Ruijs A (2006) Investing in arms to secure water. Paper presented at the international conference on economics of poverty, environment and natural resource use, 17-19 May 2006, Wageningen, The Netherlands

Janmatt J, Ruijs A (2007) Sharing the load? Floods, droughts and managing international rivers. Enivron Dev Econ 12(4):573-592

Kilgour DM, Dinar A (1995) Are stable agreements for sharing international river waters now possible? World Bank Policy Research Working Paper 1474

Kilgour DM, Dinar A (2001) Flexible water sharing within an international river basin. Environ Resour Econ 18(1):43-60

Krzysztofowicz R (2001) The case for probabilistic forecasting in hydrology. J Hydrol 249(1-4):2-9

Kucukmehmetoglu M, Guldmann JM (2004) International water resources allocation and conflicts: the case of the Euphrates and Tigris. Environ Plan A 36(5):783-801

LeMarquand D (1977) International rivers: the politics of cooperation. Westwater Research Centre, University of British Colombia, Vancouver, BC

LHDA (2005) Annual report 2004/2005. Lesotho Highlands Development Authority

Mendelsohn R, Bennett LL (1997) Global warming and water management: water allocation and project evaluation. Clim Change 37(1):271-290

Mostert E (2003) Conflict and cooperation in international freshwater management: a global review. Int J River Basin Manage 1(3):1-12

NWA (1959) Agreement between the government of the United Arab Republic and the government of Sudan for the full utilization of the Nile waters. Nile Waters Agreement, available at http://www. transboundarywaters.orst.edu/

Osborne MJ, Rubinstein A (1994) A course in game theory. MIT Press

Räisänen J, Hansson U, Ullerstig A, Doscher R, Graham LP, Jones C, Meier HEM, Samuelsson P, Willen U (2004) European climate in the late twenty-first century: regional simulations with two driving global models and two forcing scenarios. Clim Dynamics 22(1):13-31

Voss R, May W, Roeckner E (2002) Enhanced resolution modelling study on anthropogenic climate change: changes in extremes of the hydrological cycle. Int J Climatol 22(7):755-777

Wang LZ, Fang L, Hipel KW (2003) Water resources allocation: a cooperative game theoretic approach. J Environ Informatics 2(2):11-22

Wolf AT (1998) Conflict and cooperation along international waterways. Water Policy 1(2):251-265

Wu X, Whittington D (2006) Incentive compatibility and conflict resolution in international river basins: a case study of the Nile basin. Water Resour Res 42(2), W02417 